\title{
Essential Oil Extraction: Being Green and Emerging Technologies
}

\author{
Carlos Alberto Tosta Machado ${ }^{1 *}$, Herman Augusto Lepikson ${ }^{1}$, Matheus Antônio Nogueira de Andrade ${ }^{2}$, \\ Paulo Renato Câmera da Silva ${ }^{2}$ \\ ${ }^{1}$ Senai Cimatec University Center; ${ }^{2}$ Federal University of Bahia Salvador,Bahia, Brazil
}

\begin{abstract}
The essential oil extraction industry responds for a significant role as a raw material supplier to the cosmetics, pharmaceutical, and cleaning product segments. These oils are produced mainly via steam distillation in small businesses, applying systems with broad opportunities when technology is concerned. This paper aims to present the technological features to optimize extraction effectiveness (yield) and energy consumption. The answer to the question in the title involves improvement proposals to green extraction and the impact on business. This study is the continuation of the one previously published in the number 3/2021 of this Journal, entitled "Essential Oil Steam Distillation: Manufacturing 4.0".
\end{abstract}

Keywords: Essential Oil. Yield. Technology. Green Extraction.

\section{Introduction}

The essential oils (EO) extraction industry is, in general terms, supported by production systems with significant potential for technological upgrades [1]. These processes are characterized by yield uncertainties: the variability coming from the raw materials (herbs), in addition to undetected and uncorrected operational occurrences, due to the lack of basic instrumentation and control. In general, the essential oil extraction process operates in multipurpose plants, in batches, with a broad range of feedstock (leaves, branches, roots, flowers, and bark). In addition, they present variation in process cycles [2], energy, and time waste, thus with direct effects on productivity and quality, compromising the expected results. The steam distillation method is, unquestionably, the most frequently used within extraction industries $[3,4]$.

This work presents a comparative frame between the current situation and a scenario of technologically improved processes. It is based on emerging technologies that may achieve a

Received on 13 August 2021; revised 23 October 2021. Address for correspondence: Carlos Alberto Tosta Machado. SENAI CIMATEC. Avenida Orlando Gomes, Número 1845 Piatã, Zip Code: 41650-010, Salvador, Bahia, Brazil. E-mail: carlos.tosta@uol.com.br.

J Bioeng. Tech. Appl. Health 2021;4(4):128-133.

(C) 2021 by SENAI CIMATEC. All rights reserved. direct positive impact on sustainability indicators. As far as technology is concerned, the proper use of sensors and controllers [5,6], data acquisition, data treatment, followed by intelligent modeling [7] (for instance, with digital twins [8]), have the purpose of improving the steam distillation process. The detection of undesired occurrences and their correction, in the steam flow through the vegetable bed, is brought with promising proposals to optimize the extraction process toward green extraction.

Yield and extraction duration are indicators of the process performance. When optimized, these factors deliver both energy and water minimum consumption for effective production. Besides, digging down into the production chain, maximum yield requires a reduced planted area for the same produced quantity of essential oil. Therefore, it reduces all the agricultural needs and environmental impacts.

\section{Essential Oils}

Essential oils are a complex chemical mixture. Produced by secondary plant metabolic systems, they are responsible for communication with other plants, animals, attracting or repelling them, as they can be beneficial or malefic for the organism, respectively, and protection against fungi and other microorganisms. With broad use in several industries, their importance is highlighted by their customer industries: cosmetics, pharmaceutical, home care, and food preservatives [9-11]. 


\section{The Technological Scenario of the EO Industry}

The vast majority of the worldwide EO volume is produced via steam distillation. Many other methods such as organic solvents, cold pressing, micro-wave assisted, ultrasound-assisted, carbon dioxide in a critical state, and others, with smallexpression, are also found in industry, academic research, and product development areas. Nevertheless, when steam distillation is concerned, the lack of technology leads to high energy consumption, risk of poor quality, and yield loss, all due to process control and monitoring weaknesses.

According to Chemat [12], process intensification is a clear path toward green extraction with direct benefits on other business' areas as customer service, product quality, and operational costs.

Figure 1 presents the process that applies the conventional concept. Hydrosol is the odorized water obtained from the separation after condensation.

Simply explaining the process, steam is generated and flows through the plant material carrying the essential oil. Afterward, it is condensed and separated from the hydrosol. The sketch shown in Figure 1 shows the cases when the EO is lighter than the hydrosol. Just for context, some few EO's are heavier than the hydrosol.

\section{Materials and Methods}

The path to reach the purpose of the present work consists of an ordered comparison between the current state, the basic process shown in Figure 1 , and the proposed concept, with technological upgrades, as the spinal column of this paper. Among the countless possibilities, we considered a few in this comparison due to their overall process effectiveness.

The sensors, controllers, data acquisition and analysis, and intelligent modeling are tools to improve the steam distillation process. Table 1 exposes the core of the propositions to process improvements and, in consequence, sustainable performance (green extraction). PLC (Programmable Logic Controller) is the first element of process control. SCADA (Supervisory Control and Data Acquisition) is the human-

Figure 1. Essential oil conventional steam distillation process.

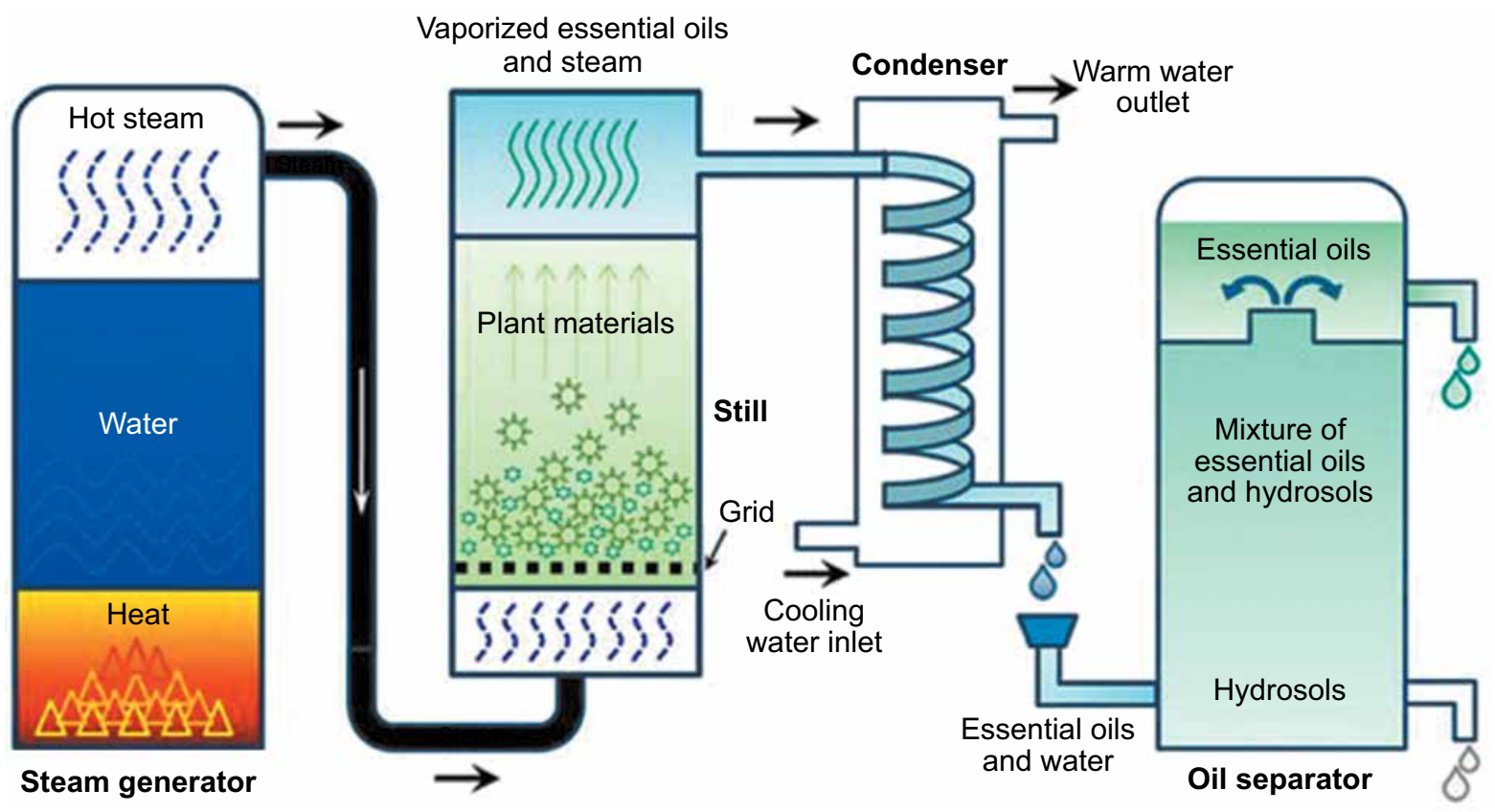


Table 1. Comparison between current and proposed situations.

\begin{tabular}{lll}
\hline & Current Status & Proposed Status \\
\hline Sensors & Few sensors, local indication & $\begin{array}{l}\text { Sensors transmitting data to PLC, SCADA } \\
\text { and A.I. }\end{array}$ \\
Data Acquisition & $\begin{array}{l}\text { No automatic data acquisition. } \\
\text { Only handwritten logbook with } \\
\text { final yield and process duration } \\
\text { information. }\end{array}$ & $\begin{array}{l}\text { All data are from sensors, operator } \\
\text { inputs, duration between main events, } \\
\text { and outputs are logged to allow } \\
\text { correlations. }\end{array}$ \\
Data Treatment & None & $\begin{array}{l}\text { Statistical analysis and search for promise } \\
\text { correlations. }\end{array}$ \\
Modeling (A.I.) & None & $\begin{array}{l}\text { Correlations allow the systematic } \\
\text { improvement of process parameters } \\
\text { coming from A.I. }\end{array}$ \\
\hline
\end{tabular}

machine interface and the center of the data acquisition system. The AI (Artificial Intelligence) is embodied in a model, searching correlations and proposing optimized process parameters [13].

The process diagrams display the differences between a conventional extraction plant, without sensors/controls, and the one instrumented to detect deviations, allowing proper control, correlations, and, consequently, process parameters optimization (Figure 2).

In this optimized proposition, conventional temperature sensors (transmitters) should be installed (Figure 3). In this conception, the thermocouples were inserted internally into the raw material bed to detect fluctuations in temperature at the points where they should be the same (or just slightly different). These differences indicate that the steam is flowing through preferential paths, named channeling by the authors. When these undesired process phenomena occur, they affect yield and quality: two indicators with primary and secondary consequences over the environmental performance.

The image processing system intends to detect the progress of the extraction curve (Figure 4) and determine the economic end-of-extraction, being $\mathrm{t} 1 \mathrm{within}$ the ramp of maximum slope, $\mathrm{t} 2$ the economic end-of-extraction time, and $\mathrm{t} 3$ the time usually used in the industry. The period between $\mathrm{t} 2$ and $\mathrm{t} 3$ shows where is the waste of energy, water, and capacity: a clear impact on the operation's overall effectiveness, including environmental care. Also, it shows the risk of product degradation, due to overexposure to high temperatures, can occur.

All correlation possibilities among yield, hydrosol weight, cooling water temperatures, and other factors like channeling correction via stepper driver action (frequency of action, duration, and magnitude of the movement) are possible due to the applied technology. The data acquisition and the data treatment indicate, batch after batch, better parameters, toward the optimized ones with modeling [7], for instance with a digital twin [8]. It means that monitoring, controlling, and providing optimized process parameters can effectively contribute to an eco-friendly operation.

\section{Results and Discussion}

The main results can be placed as a promising proposition for the essential oil industry as a technological path toward a continuous improvement production process. The prospects coming from the affirmation: "being green with technology" are clear: manufacturing facilities market development, without the properly applied technology, is impacted, reduced if none 
Figure 2. Comparison between conventional and technologically developed processes.

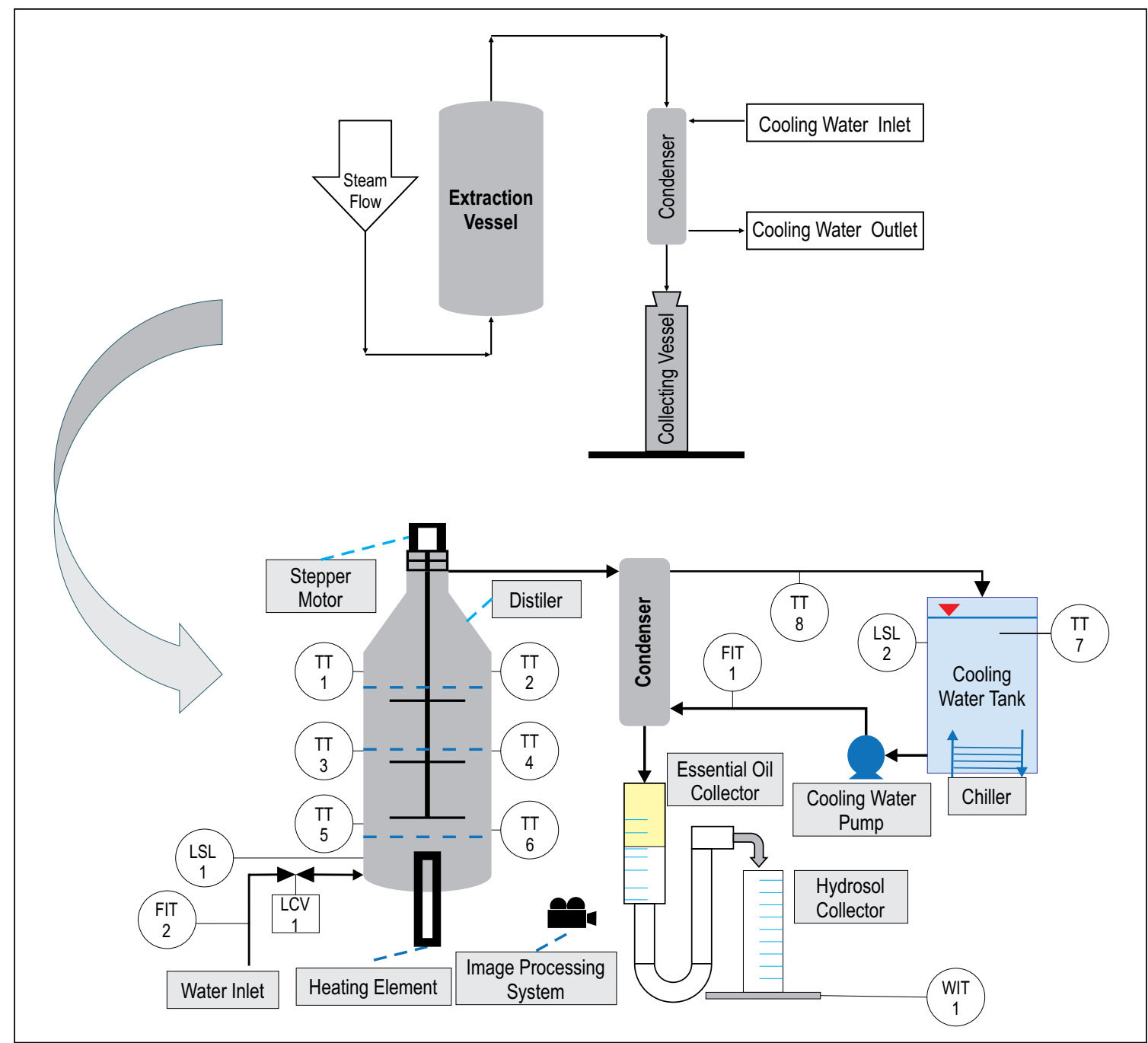

FIT: Flow Indicator and Transmitter; LCV: Level Control Valve; LSL: Level Switch Low; TT: Temperature Transmiter; WIT: Weight indicator/transmitter

when competitiveness is at the stake. The structure production (extraction, lacks control, monitoring, and continuous optimization parameters) can compromise the strategic business dimensions. Then, technology embeds opportunities for the essential oil business, with an impact on sustainability performance.

\section{Conclusion}

It is almost impossible to establish a standard solution to fit all needs in the essential oil industry. It is, indeed, not a case of "one size fits all". However, this paper is an invitation to researchers for further studies on the subject with evident beneficial consequences to a greener world.

\section{Acknowledgments}

Authors are grateful for:

- The financial support from the Bahia State Research Foundation - FAPESB through the research grant awarded (5633/2019). 
Figure 3. Channeling.

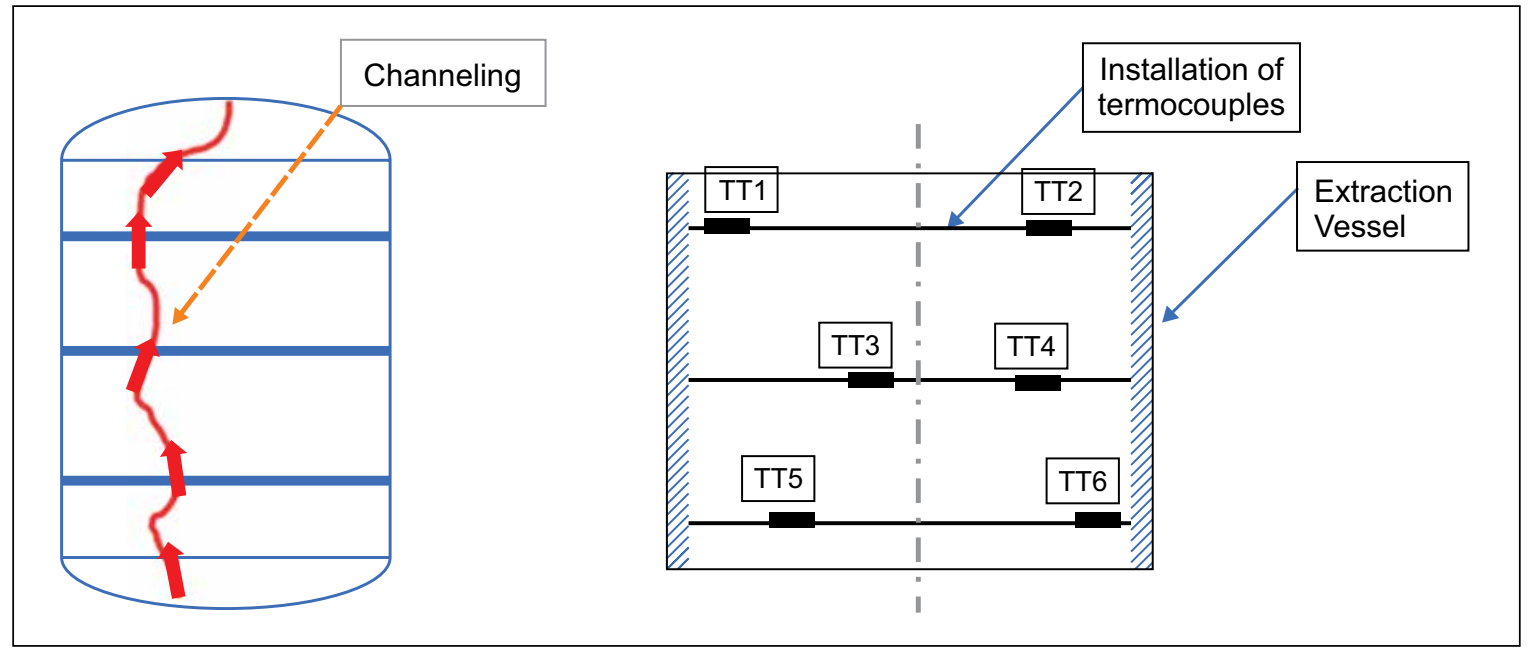

Figure 4. Optimum yield, optimum extraction time.

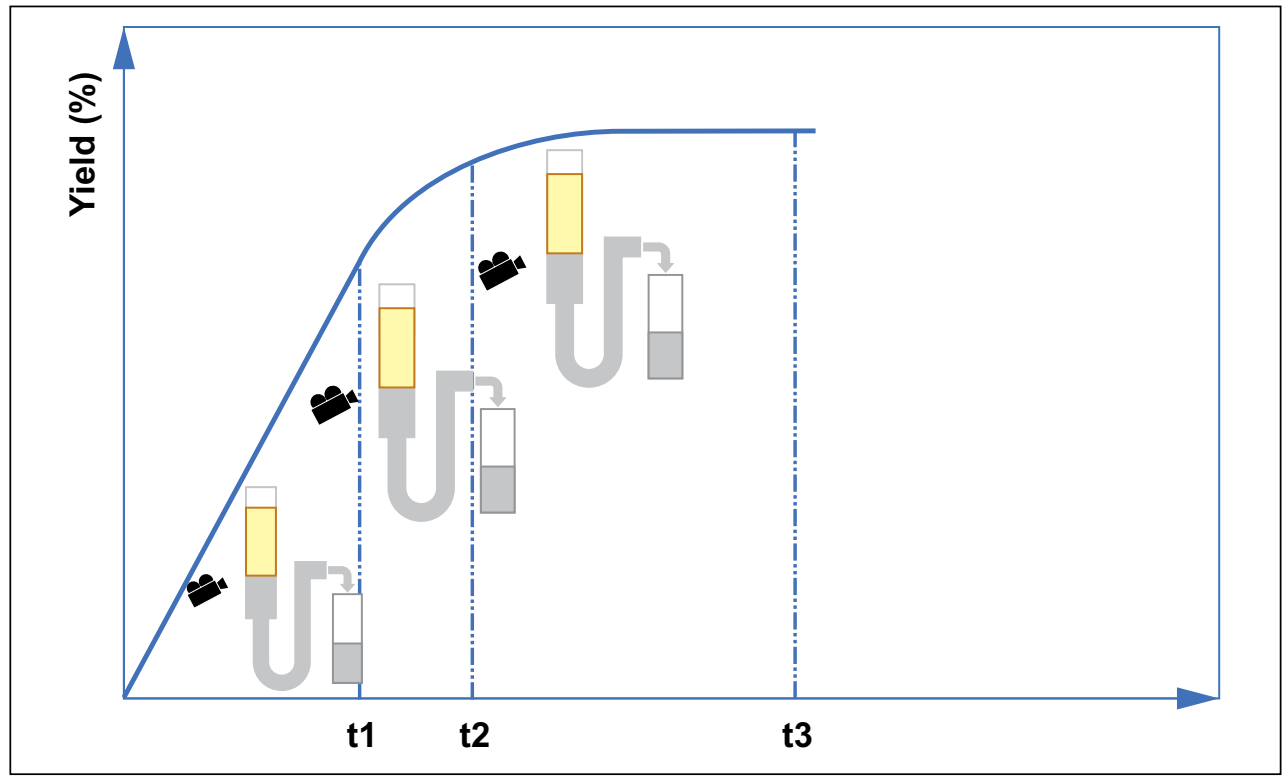

- Process equipment, control system and unvaluable recommendations for the research from Linax indústria e comércio de óleos essenciais Ltda.

- Location for the experimental phase, raw materials from the farm, energy, and water from Akã óleos essenciais Ltda.

- Cooling water unit, priced just to cover direct costs, from LimaTec equipamentos para laboratório Ltda.

\section{References}

1. Chávez MGC. Hidrodestilación de aceites esenciales: modelado y caracterización. Tese de Doutorado. Universidad de Valladolid, 2007.

2. Cannon JB, et al. Modification of yield and composition of essential oils by distillation time. Industrial Crops and Products 2013;41:214-220.

3. Baser KHC, Buchbauer G (Ed.). Handbook of essential oils: science, technology, and applications. CRC Press, 2015.

4. Chemat F, Boutekedjitey C. Extraction//steam distillation. Reference Module in Chemistry, Molecular 
Sciences, and Chemical Engineering; Elsevier: Amsterdam, The Netherlands 2015;:1-12.

5. Valderrama F, Ruiz F. An optimal control approach to the steam distillation of essential oils from aromatic plants. Computers \& Chemical Engineering 2018;117:25-31.

6. Castillo Castellanos JS, Rodrígues MCG. Diseño de la ingeniería en detalle para la repotenciación de la unidad de extracción multipropósito para prácticas no presenciales. 2021.

7. Cassel E, et al. Steam distillation modeling for essential oil extraction process. Industrial Crops and Products 2009;(29)1:171-176.

8. Andrade MAN, Lepikson HA, Machado CAT. A model proposal for digital twin development: Essential oil extraction perspective. 2021.
9. Guenther E, Althausen D. The essential oils. New York: Van Nostrand, 1948.

10. Rojas CM, et al. Regulation of primary plant metabolism during plant-pathogen interactions and its contribution to plant defense. Frontiers in Plant Science 2014;5:17.

11. Akhtar MS, Swamy MK, Sinniah UR. (Ed.). Natural bioactive compounds. Volume 1: Production and applications. Springer Nature 2019.

12. Chemat $\mathrm{F}$, et al. Green extraction of natural products. Origins, current status, and future challenges. TrAC Trends in Analytical Chemistry 2019.

13. Topaloglu F. Industrial Automation and Edge Computing SCADA PLC PAC IO-LINK-2. Turkish Journal of Science and Technology 2021;(16):1:179185. 